\title{
Microstructural Design for High-Strain-Rate Superplastic Oxide Ceramics
}

\author{
Keijiro HIRAGA, Byung-Nam KIM, Koji MORITA, Tohru S. SUZUKI and Yoshio SAKKA \\ National Institute for Material Science, 1-2-1, Sengen, Tsukuba-shi, Ibaraki 305-0047
}

\author{
酸化物系高速超塑性セラミックスの組織設計 \\ 平賀啓二郎·金 炳男·森田孝治 ·鈴木 達·目 義雄 \\ 物質・材料研究機構材料研究所, 305-0047 つくば市千現 1-2-1
}

\begin{abstract}
Factors limiting the strain rate available to superplastic deformation in oxide ceramics are discussed from existing knowledge about high-temperature plastic deformation and cavitation mechanisms. Simultaneously controlling these factors is essential for attaining high-strain-rate superplasticity (HSRS). This is shown in monolithic tetragonal zirconia and composite materials consisting of zirconia, $\alpha$-alumina and a spinel phase: at strain rates higher than $10^{-2} \mathrm{~s}^{-1}$, tensile ductility reached $300-600 \%$ in the monolithic material and $600-2500 \%$ in the composite materials. Post-deformation microstructure indicates that certain secondary phases should be effective in suppressing cavitation damage and thereby enhancing HSRS.
\end{abstract}

[Received October 29, 2004; Accepted December 15, 2004]

Key-words : High-strain-rate superplasticity, Grain-boundary sliding, Accommodation, Stress relaxation, Cavity nucleation, Cavity growth, Dynamic grain growth

1. Introduction

Substantial superplasticity is defined as the ability of a material to exhibit tensile ductility (elongation) larger than $200 \%$, where the ductility is defined as $e_{\mathrm{f}}=100\left(l_{\mathrm{f}}-l_{0}\right) / l_{0}$ for the initial $\left(l_{0}\right)$ and the final $\left(l_{\mathrm{f}}\right)$ lengths of the material. In ceramic materials, this ability was first found by Wakai et $a{ }^{1}{ }^{1)}$ and has provided a unique opportunity of net shaping and joining of non-metallic materials. In ceramic materials, however, industrial applications of superplasticity have been highly limited, in contrast to superplastic metallic materials. ${ }^{2)-4)}$ This is because superplasticity in most ceramics occurs at low strain rates around $10^{-5}-10^{-4} \mathrm{~s}^{-1}$ even at high temperatures of $1400-1650^{\circ} \mathrm{C}$. At a strain rate of $10^{-4} \mathrm{~s}^{-1}$, for example, it takes about $2.8 \mathrm{~h}$ to elongate a material having an initial length of $10 \mathrm{~mm}$ to a final length of $20 \mathrm{~mm}$. Such a long forming time is unallowable in industry. The forming time can be reduced to shorter than $100 \mathrm{~s}$, when the material is formable at a strain rate higher than $10^{-2} \mathrm{~s}^{-1}$. In metallic materials, superplasticity at a strain rate higher than $10^{-2} \mathrm{~s}^{-1}$, namely high-strain-rate superplasticity (HSRS) is a key of commercial net-shaping, ${ }^{3), 4)}$ and so should be in ceramic materials.

This paper addresses HSRS in oxide ceramics and discusses earlier and recent results obtained in this field. First, factors necessary for attaining HSRS are extracted from existing knowledge about superplasticity and relating phenomena. In the light of the extracted factors, discussion is given to the results of earlier studies on superplastic oxides. Finally, an overview of our recent trials is given with discussion about some noticeable aspects newly found in the trials.

\section{Prerequisites for attaining HSRS in oxide ceramics}

2.1 Creep equation

Since a ceramic material can be regarded as an aggregate of rigid grains, a couple of grain-boundary sliding and grain switching accommodated by diffusion (Fig. 1) has been regarded as the main mechanism of superplastic deformation. ${ }^{5)}$,6) If the processes of accommodation occur ideally uniform and successive, then superplastic deformation takes place also uniformly and successively without intergranular

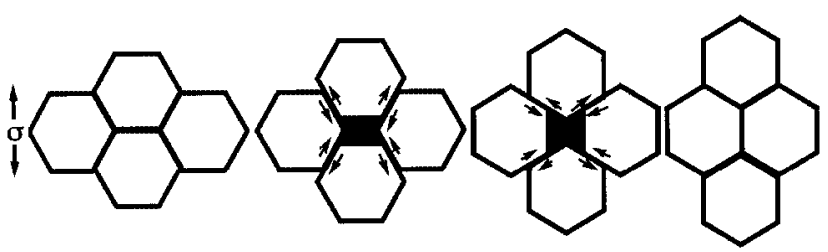

Fig. 1. A 2-D model ${ }^{7)}$ for grain-boundary sliding and grain switching during superplastic deformation.

cavitation. For such an ideal case, the conventional creep equation (Eq. (1)) tells that the strain rate, $\dot{\varepsilon}$, for a given combination of stress, $\sigma$, and temperature, $T$, can be heightened by a reduction in the grain size, $d$, and an increase in the $A$ exp $(-Q / R T)$ term.

$$
\dot{\varepsilon}=A \exp (-Q / R T) \sigma^{n} d^{-p},
$$

where $A$ is a material constant, $Q$ is the activation energy, $R$ is the gas constant, $n$ is the stress exponent and $p$ is the grain-size exponent. An increase in $A \exp (-Q / R T)$ can be attained by enhanced grain-boundary and/or lattice diffusion; doping of some aliovalent cations is empirically known to be effective for this purpose.

In actual materials, however, the accommodation processes do not take place ideally. We should also note that Eq. (1) does not give any information on the following dynamic phenomena. Superplastic deformation is inherently accompanied by accelerated grain growth (dynamic grain growth) ${ }^{8)}$ and intergranular cavitation. ${ }^{9)-12}$ The former increases the stress level for a given strain rate and enhances the latter, leading to premature failure and degradation in post-deformation strengths. ${ }^{13)}$ Consideration to these phenomena is essential for the attainment of HSRS and its application.

2.2 Stress concentrations and cavity nucleation

Existing theories and models for intergranular cavitation $^{14), 16)}$ tell that cavity nucleation occurs owing to stress concentrations that relate closely to the inhomogeneity of 

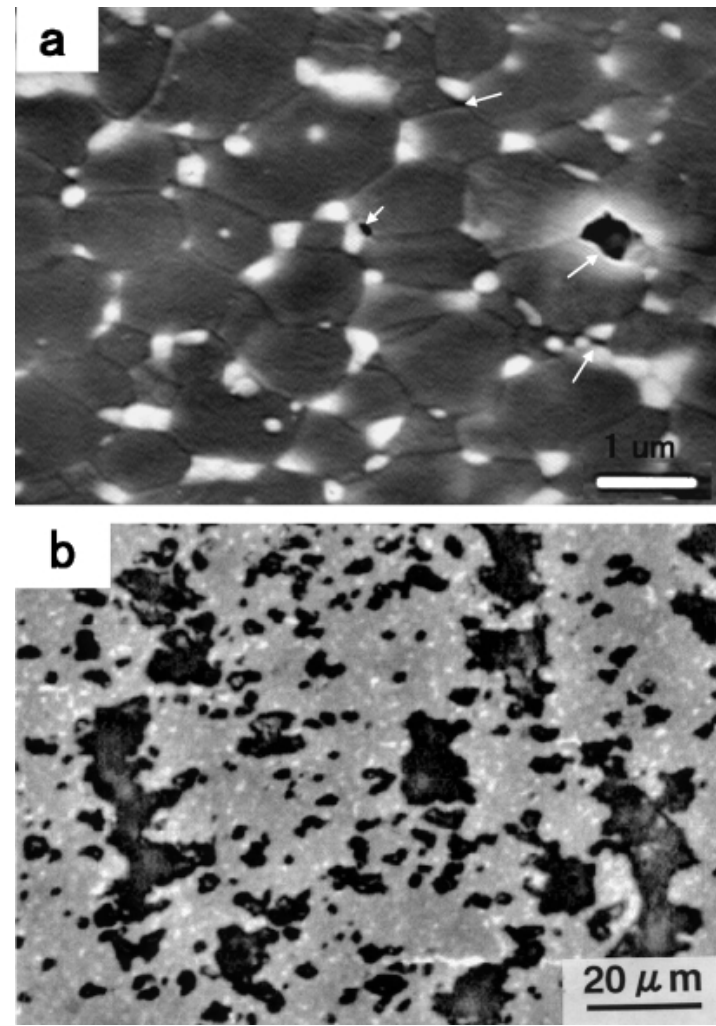

Fig. 2. Cavitation damage accompanying superplastic tensile deformation in a $10 \mathrm{vol} \% \mathrm{ZrO}_{2}(3 \mathrm{Y})$ dispersed $\mathrm{Al}_{2} \mathrm{O}_{3}$ : (a) cavity nucleation at multiple junctions and phase boundaries and (b) microcracking due to coalescence of micrometer-sized voids grown from cavity nuclei and preexistent defects. Tensile axis is horizontal.

microstructures and chemical compositions. Even in a monolithic material, there are distributions of grain size, grain shape and chemical composition. Owing to this fact, stress distribution and chemical potential, and hence grain-boundary sliding and grain switching coupled with diffusion also become inhomogeneous in a microscopic scale. There is consequently a finite probability of the breakdown of the accommodation processes, particularly in some localized portions where the geometry and the chemical composition are steeply changed. This situation means equivalently that in such portions, stress concentrations caused by grain-boundary sliding cannot always be relaxed sufficiently by diffusion. ${ }^{14), 15)}$ Typical examples of such portions are multiple grain junctions and phase boundaries, where cavity nuclei have frequently been observed after superplastic deformation (Fig. $2(\mathrm{a})$ ).

Although the detailed relationship among stress concentrations or relaxation, diffusion and cavity nucleation has not been established yet in superplastic ceramics, estimation is available to this issue. For an aggregate of a tetrakaidecahedron having a facet length of $d / 3$, the existing models give the following estimation to the critical grain size, $d_{\mathrm{c}}$, that can be relaxed by grain-boundary diffusion. We define the critical size as $d_{\mathrm{c}}=3 \Lambda$, where $\Lambda$ is given by Eq. (2) and represents the length over which grain-boundary diffusion relaxes the stress concentrations caused by deformation. ${ }^{14)}$

$$
\frac{\Lambda}{d}=\left(\frac{L}{d}\right)^{\frac{1}{[1-\mathrm{s}(n-1) / 3]}}
$$

where $L$ is the characteristic diffusive length given by Eq. (3) and $s$ is the extent of stress singularity at the triple point.

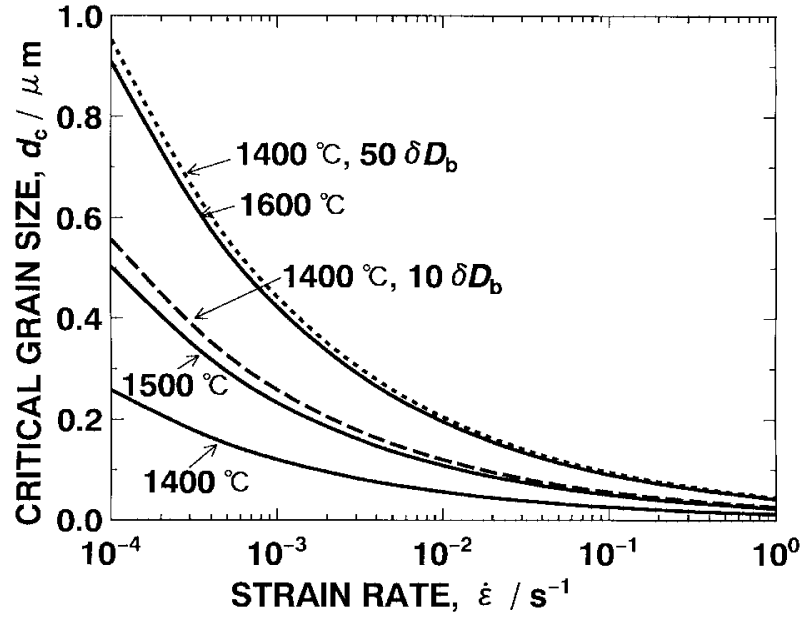

Fig. 3. Estimation of the critical grain size over which grain-boundary diffusion can relax stress concentrations caused by deformation.

$$
L=\left(\frac{\delta D_{\mathrm{gb}} \sigma \Omega}{k_{\mathrm{B}} T \dot{\varepsilon}}\right)^{1 / 3}
$$

where $\delta D_{\mathrm{gb}} \propto \exp (-Q / R T)$ is the grain-boundary diffusion coefficient, $\Omega$ is the atomic volume and $k_{\mathrm{B}}$ is the Boltzmann constant. Using the diffusion data for a Ce-doped tetragonal $\mathrm{ZrO}_{2}{ }^{17)}$ and assuming $n=3, \sigma=30 \mathrm{MPa}$ and a dihedral angle of $120^{\circ}$, for which $s$ becomes 0.45 , we obtain Fig. 3. When $d_{c}$ is smaller than the grain size, stress relaxation becomes insufficient, leading to active cavity nucleation. In an extreme case of $d \gg d_{\mathrm{c}}$ at large $\sigma$, instantaneous de-bonding may occur at grain-boundaries or interfaces.

Figure 3 indicates that the critical grain size decreases steeply with an increase in the strain rate. At $1400^{\circ} \mathrm{C}$, for example, the estimation predicts that a grain size of $0.26 \mu \mathrm{m}$ is sufficient to obtain ordinary superplasticity at $10^{-4} \mathrm{~s}^{-1}$, whereas a grain size of $0.06 \mu \mathrm{m}$ is necessary to attain HSRS at $10^{-2} \mathrm{~s}^{-1}$. For a grain size of $0.2 \mu \mathrm{m}$, a temperature higher than $1600^{\circ} \mathrm{C}$ is necessary to attain $10^{-2} \mathrm{~s}^{-1}$. Grain-size reduction and suppressed grain growth are thus essential for sufficient stress relaxation and suppressed cavity nucleation during highstrain-rate deformation. The estimation also indicates that an increase in the diffusivity by a factor of 10 and 50 corresponds to an increase in the temperature by about $100^{\circ} \mathrm{C}$ and $200^{\circ} \mathrm{C}$, respectively. In the latter, stress relaxation at $10^{-2} \mathrm{~s}^{-1}$ is expected to become sufficient for $d=0.2 \mu \mathrm{m}$ even at $1400^{\circ} \mathrm{C}$. Thus, enhanced diffusion for a given grain size is also essential for attaining HSRS at a lower temperature.

The existing models ${ }^{14)-16)}$ also predict the following characteristics of cavity nucleation. The probability of cavity nucleation depends on the level of flow stress, the grain-boundary diffusivity, the surface energy $\gamma_{\mathrm{s}}$, the grain-boundary energy $\gamma_{\mathrm{b}}$ and geometrical factors such as the dihedral angle between the grain facets. For a given grain size, for example, the probability of cavity nucleation decreases with increasing $\delta D_{\mathrm{b}}$ and $\gamma_{\mathrm{s}}$ and with decreasing $\sigma$ and $\gamma_{\mathrm{b}}$. Since the rate of nucleation depends on $\exp \left(-1 / \sigma^{2}\right)$, reduction in the flow stress level is of particular importance.

\subsection{Cavity growth and tensile failure}

During superplastic deformation, fine defects remaining after sintering and cavity nuclei grow into micrometer-sized voids (Fig. 2), and the interlinkage of the voids causes cracking along a direction perpendicular to the stress axis (Fig. 2 (b) $).{ }^{9), 10), 12), 18)}$ In this process, there appears a close similarity 
to that of ductile failure in metallic materials containing microvoids or hard inclusions. ${ }^{18)}$

In zirconia- ${ }^{19)}$ and alumina-based ${ }^{12), 19), 20)}$ materials, the growth of micrometer-sized voids has been observed to obey $\mathrm{d} D / \mathrm{d} \varepsilon=\eta D$, where $D$ is the cavity diameter and $\eta$ is a constant taking a value of about unity. This growth law means that the voids are grown by the plastic flow of the material. ${ }^{14), 21)}$ Such a plastic mechanism is not contradictory to the fact that the grains are rigid, since the aggregate of the rigid grains surrounding the micrometer-sized voids behaves as a plastic body in superplastic ceramics. In the plastic mechanism, the increment of void volume during deformation is determined by the increment of plastic strain. For this reason, the void growth can hardly be controlled by the modifications of chemical compositions and microstructure. For the suppression of damage accumulation arising from the void growth, it is essential to reduce the number of residual defects in the sintered body and to suppress cavity nucleation during deformation.

\subsection{Dynamic grain growth}

The major importance of suppressed grain growth is to keep the flow stress in a low level during superplastic loading (Eq. (1)). A lowered level of flow stress is necessary for suppressed cavity nucleation as described above. A model ${ }^{22}$ derived from a diffusion mechanism gives the following equation for constant displacement-rate loading. ${ }^{12)}$

$$
d=\left[d_{0}{ }^{m} \exp (\alpha m \varepsilon)+\frac{k\{\exp (\varepsilon)-\exp (\alpha m \varepsilon)\}}{\dot{\varepsilon}_{0}(1-\alpha m)}\right]^{1 / m},
$$

where $d_{0}$ is the initial grain size, $\alpha$ is a constant depending on the grain shape and the grain-size distribution, $m$ and $k$ are the grain-growth exponent and the kinetic constant, respectively, of the static grain-growth law, $d^{m}-d_{0}{ }^{m}=k t$, where $t$ is the heating time. Equation (4) indicates that the grain size for a given strain becomes smaller with a reduction in the initial size and an increase in the deformation rate. In addition, experimental data indicate that the value of $\alpha$ for superplastic deformation is rather insensitive to chemical compositions: about $0.5-0.6$ for some oxide materials $\left(\mathrm{ZrO}_{2}-\mathrm{Al}_{2} \mathrm{O}_{3},{ }^{12), 22)} \mathrm{ZrO}_{2}-\mathrm{MgAl}_{2} \mathrm{O}_{4-}\right.$ $\left.\mathrm{Al}_{2} \mathrm{O}_{3},{ }^{23)} \mathrm{ZrO}_{2}(3 \mathrm{Y})^{24)}\right)$ and superplastic metals $\left(\mathrm{Zn}-\mathrm{Al}^{22)}\right)$. The outline of dynamic grain-growth can thus be estimated from the values of $k$ and $m$. It is consequently essential to suppress static grain growth by grain-boundary pinning and/or dragging.

\subsection{Minor additives}

In superplastic ceramics, deformation behavior and tensile ductility are known to be sensitive to some minor additives or impurity elements. ${ }^{25)}$-27) This fact has typically been observed in monolithic $3 \mathrm{Y}-\mathrm{TZP}^{28)-34)}$ : tensile ductility for a relative density of $\geq 99 \%$ depends strongly on minor additives, although the additives do not introduce any solid or glass phases along grain-boundaries nor at multiple junctions.

To explain the experimental data, Sakuma et al. ${ }^{27), 30)-34)}$ have taken an approach based on a first-principle molecularorbital calculation for model clusters. They found a close relationship between tensile ductility at $\sim 10^{-4} \mathrm{~s}^{-1}$ and the total bond-overlap population (BOP) that represents the strength of covalent bonding among the constitutive ions: increasing ductility with increasing BOP. For additions of $\mathrm{Ti}^{4+}$ and/or $\mathrm{Ge}^{4+}$ to $3 \mathrm{Y}-\mathrm{TZP}$, they have also found a close relationship between flow stress and the average product of net charge, $\Theta$, calculated for a model cluster consisting of zirconium ion, doped cation and oxygen ion. Since the level of flow stress reflects diffusivity for a fixed combination of the grain size, strain rate and temperature, the above result also indicates a close relationship between $\Theta$ and diffusivity. This approach has an essential merit of positioning the additives in the $\Theta-\sigma$ and BOP- $e_{\mathrm{f}}$ fields through the molecular-orbital calculation. Although the minute relationship with the classical parameters such as $\gamma_{\mathrm{b}}, \gamma_{\mathrm{s}}$ and $\delta D_{\mathrm{b}}$ are not clear at this moment, a study ${ }^{34)}$ on $\mathrm{Y}-\mathrm{TZP}$ doped with $\mathrm{Ge}^{4+}, \mathrm{Ti}^{4+}$ or $\mathrm{Ba}^{2+}$ have indicated a close relationship between the covalence and $\gamma_{\mathrm{b}}$.

The following consideration based on the cavitation models ${ }^{14)-16)}$ suggests that the above explanation relates closely to the ability of cavity nucleation. For a fixed combination of the major chemical composition, initial grain size, grain shape, size distribution of residual defects and loading conditions, the cavitation models predict that tensile ductility should strongly be controlled by the rate of cavity nucleation. The nucleation rate in this case should depend mainly on $\gamma_{b}, \gamma_{s}$ and $\delta D_{\mathrm{b}}$, since the other parameters are fixed. When $\gamma_{\mathrm{b}}, \gamma_{\mathrm{s}}$ and $\delta D_{\mathrm{b}}$ are sensitive to some cations with valences and/or ionic radii different to those of the matrix cations, ${ }^{25)}$ so should be the cavity nucleation rate and hence superplastic ductility. Since the kinetic constant of grain growth (Eq. (4)) depends on $\gamma_{\mathrm{b}}$ and $\delta D_{\mathrm{b}}$, the doped cations may additionally influence cavity nucleation through varying the rate of dynamic grain growth that affects the flow stress of Eq. (1).

\subsection{Guide for attaining HSRS}

From the above-described discussion, factors necessary or desirable for attaining HSRS can be summarized as Table 1. We should note that some of the factors may concomitantly produce positive and negative effects. For example, although second-phase pinning should be effective in suppressing dynamic grain growth, it may provide a site of stress concentrations for cavity nucleation. A minor additive that enhances diffusion is also the case: the additive should simultaneously enhance stress relaxation and dynamic grain growth. We should also note that some factors are strongly processing dependent. A study ${ }^{12)}$ on $\mathrm{ZrO}_{2}$-dispersed $\mathrm{Al}_{2} \mathrm{O}_{3}$ showed that ductility for a given initial grain size was a factor of $\sim 2.5$ larger in a material prepared by colloidal processing than in a material prepared by conventional dry processing. This result is attributed to differences in the size distributions of fine defects and dispersed $\mathrm{ZrO}_{2}$ particles. The former affects the accumulation of micrometer-sized voids and the latter concerns the rate of cavity nucleation through the rate of dynamic grain growth. ${ }^{12)}$ Each factor listed in Table 1 has often been discussed in studies on conventional superplasticity, whereas there have still been few studies that consider these points simultaneously.

\section{Earlier studies on HSRS in oxide ceramics}

In earlier studies on ceramics, tensile elongation exceeding $200 \%$ at a strain rate of $10^{-2} \mathrm{~s}^{-1}$, namely HSRS was reported by Chokshi et al. ${ }^{10)}$ for a commercial 20-mass $\%-\mathrm{Al}_{2} \mathrm{O}_{3}$ dispersed $\mathrm{ZrO}_{2}(3 \mathrm{Y})$, by Kajihara et al. ${ }^{35)}$ for a 5-mass\%$\mathrm{SiO}_{2}$-doped $\mathrm{ZrO}_{2}(2.5 \mathrm{Y})$ and by $\mathrm{Oka}$ et al. ${ }^{36)}$ for a $\mathrm{ZrO}_{2}(3 \mathrm{Y})$ co-doped with $2 \mathrm{~mol} \% \mathrm{TiO}_{2}$ and $2 \mathrm{~mol} \% \mathrm{CaO}$. Noticeable points in the materials are summarized in Table 2. The materials have fine grain sizes of about $0.3 \mu \mathrm{m}$ and the matrices consist of yttria-stabilized tetragonal zirconia (Y-TZP). The latter is a particular advantage in attaining HSRS, since grain growth in Y-TZP is sluggish as compared to that in other materials such as Ce-TZP, cubic zirconia and alumina-base materials. $^{25)}$

Although the data on the $\mathrm{Al}_{2} \mathrm{O}_{3}$-dispersed $\mathrm{ZrO}_{2}{ }^{10)}$ was reported without any comment on HSRS, tensile elongation reached $\sim 300 \%$ at $1650^{\circ} \mathrm{C}$ and at a strain rate of $4 \times 10^{-2} \mathrm{~s}^{-1}$. In the light of Table 1, the material has two additional advan- 
Table 1. Guide for Attaining HSRS

\begin{tabular}{ll}
\hline necessary or desirable factors & relating factors or phenomena \\
\hline (a) reduced initial grain size & $\begin{array}{l}\text { strain rate, stress relaxation, cavity nucleation } \\
\text { (processing-dependent) }\end{array}$ \\
\hline (b) suppressed dynamic grain growth & $\begin{array}{l}\text { Stress concentrations, cavity nucleation } \\
\text { (second-phase pinning and dragging: } \\
\text { processing-dependent) }\end{array}$ \\
\hline (c) enhanced diffusivity & $\begin{array}{l}\text { strain rate, stress relaxation, cavity nucleation } \\
\text { (doping of aliovalent cations) }\end{array}$ \\
\hline (d) homogeneous microstructure & $\begin{array}{l}\text { dynamic grain growth, cavity nucleation } \\
\text { (processing-dependent) }\end{array}$ \\
\hline (e) reduced residual defects & $\begin{array}{l}\text { damage due to micrometer-sized cavities } \\
\text { (processing-dependent) }\end{array}$ \\
\hline (f) low $\gamma_{\mathrm{b}}$ and high $\gamma_{\mathrm{s}}$ & $\begin{array}{l}\text { cavity nucleation } \\
\text { (grain-boundary segregation) }\end{array}$ \\
\hline (g) enhanced accommodation \\
(by a viscous phase) & $\begin{array}{l}\text { cavity nucleation } \\
\text { (glass-phase dispersion, intergranular }\end{array}$ \\
\hline (h) additional accommodation \\
(by limited intragranular plasticity ${ }^{*}$ Si-segregation)
\end{tabular}

Table 2. Oxide Ceramics Exhibiting High-Strain-Rate Superplasticity

\begin{tabular}{|c|c|c|c|c|c|c|}
\hline $\begin{array}{l}\text { Symbols } \\
\text { (Fig. 4) }\end{array}$ & Material & $\begin{array}{l}\text { Necessary } \\
\text { or desirable } \\
\text { factors }\end{array}$ & $\dot{\varepsilon}_{0} / \mathrm{s}^{-1}$ & $e_{\mathrm{f}}(\%)$ & $T /{ }^{\circ} \mathrm{C}$ & Ref. \\
\hline & $20 \mathrm{Al}_{2} \mathrm{O}_{3}-\mathrm{ZrO}_{2}(3 \mathrm{Y})^{\mathrm{a}}$ & (b), (c) & 0.04 & 300 & 1650 & 10) \\
\hline & $5 \mathrm{SiO}_{2}-\mathrm{ZrO}_{2}(2.5 \mathrm{Y})^{\mathrm{b}}$ & (b), (e)-(g) & 0.01 & 360 & 1400 & 35) \\
\hline & $2 \mathrm{CaO}-2 \mathrm{TiO}_{2}-\mathrm{ZrO}_{2}(3 \mathrm{Y})^{\mathrm{c}}$ & (b), (c) & 0.01 & 400 & 1400 & 36) \\
\hline$\nabla$ & $0.2 \mathrm{Al}_{2} \mathrm{O}_{3}-\mathrm{ZrO}_{2}(3 \mathrm{Y})^{\mathrm{a}}$ & (a), (c)-(e) & 0.03 & 370 & 1450 & 37) \\
\hline$\Delta$ & $3\left(\mathrm{Y}_{2} \mathrm{O}_{3}, \mathrm{MgO}\right)-97\left(\mathrm{Zr}_{0.95} \mathrm{Ti}_{0.05}\right) \mathrm{O}_{2}^{\mathrm{b}}$ & (a), (c)-(e) & 0.01 & 220 & 1350 & 42) \\
\hline & & & 0.01 & 300 & 1450 & \\
\hline$\diamond$ & $0.2 \mathrm{Mn}_{3} \mathrm{O}_{4}-0.3 \mathrm{Al}_{2} \mathrm{O}_{3}-\mathrm{ZrO}_{2}(3 \mathrm{Y})^{\mathrm{b}}$ & (a), (c)-(e) & 0.01 & 600 & 1450 & 43) \\
\hline$\bigcirc$ & $40 \mathrm{ZrO}_{2}(3 \mathrm{Y})-30 \mathrm{MgAl}_{2} \mathrm{O}_{4}-\mathrm{Al}_{2} \mathrm{O}_{3}{ }^{\mathrm{c}}$ & (a)-(d), (h) & 0.01 & 500 & 1500 & $44-46)$ \\
\hline & & & 0.08 & 2500 & 1650 & \\
\hline & & & 1.0 & 390 & 1650 & \\
\hline$\triangle$ & $30 \mathrm{ZrO}_{2}(3 \mathrm{Y})-30 \mathrm{MgAl}_{2} \mathrm{O}_{4}-\mathrm{Al}_{2} \mathrm{O}_{3}{ }^{\mathrm{c}}$ & (a)-(d), (h) & 0.02 & 660 & 1450 & $47,48)$ \\
\hline & & & 0.7 & 250 & 1550 & \\
\hline
\end{tabular}

${ }^{a} \mathrm{mass} \%$. ${ }^{\mathrm{b}}$ mol\%. ${ }^{\mathrm{c}}$ vol\%. ${ }^{\mathrm{d}}$ see Table 1. ${ }^{\mathrm{e}}$ see section 4.4

tages in attaining HSRS. The dispersed $\mathrm{Al}_{2} \mathrm{O}_{3}$ particles may contribute not only to the suppression of grain growth, but also to the enhancement of diffusion through supplying $\mathrm{Al}^{3+}$ to the $\mathrm{ZrO}_{2}$ matrix. The latter effect is strongly suggested from studies $^{37)-39)}$ on Y-TZP doped with a small amount of $\mathrm{Al}_{2} \mathrm{O}_{3}$.

The doping of 5 mass $\%$ pure $\mathrm{SiO}_{2}$ was intended to enhance superplasticity and attained tensile ductility reaching to $1050 \%$ at $1.3 \times 10^{-4} \mathrm{~s}^{-1}$ and HSRS where elongation reached $390 \%$ at $1.3 \times 10^{-2} \mathrm{~s}^{-1} .^{35)}$ High-resolution electron microscopy ${ }^{40)}$ combined with energy dispersive X-ray spectroscopy revealed that $\mathrm{SiO}_{2}$-addition does not introduce intergranular glassy films, but causes intergranular segregation of $\mathrm{Si}^{4+}$. The molecular-orbital calculation led to a conclusion that the $\mathrm{Si}$ segregation should strengthen the grain-boundary bonding in Y-TZP and thereby enhance superplastic tensile ductility. In the cavitation mechanisms, the explanation may correspond to an increase in $\gamma_{\mathrm{s}}$ and/or a decrease in $\gamma_{\mathrm{b}}$, both of which should lead to suppressed cavity nucleation. In addition, the viscous flow of $\sim 12$ vol $\%$ of a silica phase dispersed at multiple grain junctions may suppress stress concentrations around the multiple junctions and hence cavity nucleation. It should also be noted that the silica phase suppresses grain growth. ${ }^{40), 41)}$ In the $\mathrm{SiO}_{2}$ addition, we can thus pick up three additional advantages to HSRS.

The co-doping of $\mathrm{CaO}$ and $\mathrm{TiO}_{2}$ is probably the first example of a design of chemical composition intending to attain HSRS in a ceramic material. The following merits were expected from the co-doping: suppressed grain growth due to dragging from $\mathrm{CaO}$ and enhanced diffusivity from $\mathrm{TiO}_{2} \cdot{ }^{36)}$ The co-doping resulted in a dual-phase structure consisting of 22 vol\% cubic and $78 \%$ tetragonal phases and led to HSRS: tensile ductility reached $404 \%$ at $1.1 \times 10^{-2} \mathrm{~s}^{-1}$. It has not been clarified yet whether the dispersed cubic phase may play a positive or negative role in HSRS. Inspection of these earlier data indicates that, of the necessary factors listed in Table 1, four or more should be satisfied for attaining HSRS. 


\section{Recent trials for attaining HSRS in oxide ceramics} 4.1 Processing

Placing special attention on necessary factors (a) through (e) of Table 1, the present authors tried to attain HSRS in both monolithic ${ }^{37), 42), 43)}$ and composite materials, ${ }^{44)-48)}$ without using glassy phases. We also noted that factors (a), (b) , (d) and (e) are processing dependent. This is particularly the case, when we use fine powders that tend to agglomerate spontaneously owing to van der Waals forces. ${ }^{49)}$ The agglomeration forms large pores in green bodies, and the pores cannot be eliminated by sintering at a lower temperature. To prevent agglomeration, we applied colloidal processing ${ }^{50)}$ to fine oxide powders.

\subsection{Tetragonal zirconia}

Since grain-growth is inherently sluggish in Y-TZP, factors (a), (c), (d), (e) and (f) should be the keys for attaining HSRS. Of these factors, we tried to control (a) and (c) through (e). To enhance diffusion, we doped or co-doped aliovalent cations using commercial high-purity powders of $\alpha$ $\mathrm{Al}_{2} \mathrm{O}_{3}{ }^{37)}, \mathrm{Mn}_{3} \mathrm{O}_{4}{ }^{43)}$ and $\mathrm{MgO} .{ }^{42)} \mathrm{We}$ also used $\mathrm{TiO}_{2}{ }^{42)}$ since experimental data ${ }^{34), 51)}$ for grain growth and superplastic properties indicate that diffusion in $\mathrm{Y}-\mathrm{TZP}$ is enhanced by $\mathrm{TiO}_{2}$ addition. For the $\mathrm{TiO}_{2}$-addition, we co-doped $\mathrm{MgO}$ aiming at the stabilization of the tetragonal phase. ${ }^{42}$ Using colloidal processing followed by sintering at $1300^{\circ} \mathrm{C}$ for $2 \mathrm{~h}$, almost fully densified bodies were obtained in an $\mathrm{Al}_{2} \mathrm{O}_{3}$-doped 3Y-TZP and a Y-TZP co-doped with $\mathrm{TiO}_{2}$ and $\mathrm{MgO}$ or with $\mathrm{Mn}_{3} \mathrm{O}_{4}$ and $\mathrm{Al}_{2} \mathrm{O}_{3}$ (Table 2). The sintered materials consisted of a single tetragonal phase with an average grain size of 0.23 $\mu \mathrm{m}$, where the size was defined as 1.56 times the average intercept length of the grains. Examinations of sintering behavior and the rate of static grain-growth indicated enhanced diffusion.

These materials exhibited HSRS at around $1400^{\circ} \mathrm{C}$ and at a rate of the order of $10^{-2} \mathrm{~s}^{-1}$. By the co-doping of $\mathrm{TiO}_{2}$ and $\mathrm{MgO}$, the deformation temperature can be lowered to $1350^{\circ} \mathrm{C}$. This is the lowest temperature that has reported for HSRS in ceramics and locates in a lower temperature limit for conventional superplasticity in $\mathrm{Y}-\mathrm{TZP}$. A maximum tensile elongation of $660 \%$ was obtained by co-doping of $\mathrm{Mn}_{3} \mathrm{O}_{4}$ and $\mathrm{Al}_{2} \mathrm{O}_{3}$.

\subsection{Composites}

The following merits can be expected in composite materials: strongly suppressed dynamic grain growth and improved fracture strengths. ${ }^{52)}$ When a tetragonal zirconia is dispersed in the composites, transformation toughening can be expected below the transformation temperature. Despite these merits, we should note that strong grain-boundary pinning may simultaneously work to impede grain-boundary sliding. For this reason, enhanced diffusion is indispensable in the matrix. In addition, the elimination of agglomeration in raw materials is of particular importance in composites. For a given value of the relative density, lower extent of agglomeration enables us to sinter the material at a lower temperature and thereby obtain a finer grain size.

Of the factors listed in Table 1, we thus tried to control (a), (c), (d) and (e). We examined second-phase pinning and a tri-phase structure where the volume fraction of each phase was similar. In the tri-phase structure, we can expect strongly suppressed grain growth, since the frequency of the grain boundaries is decreased between the same phases and the diffusion distance is accordingly increased between the phases. ${ }^{44)}$ For a large amount of second-phase dispersion, for which clustering of the phase is unavoidable, we used such a secondary phase that exhibits superplastic or superplastic-like deformation. From these considerations, we examined a sys-

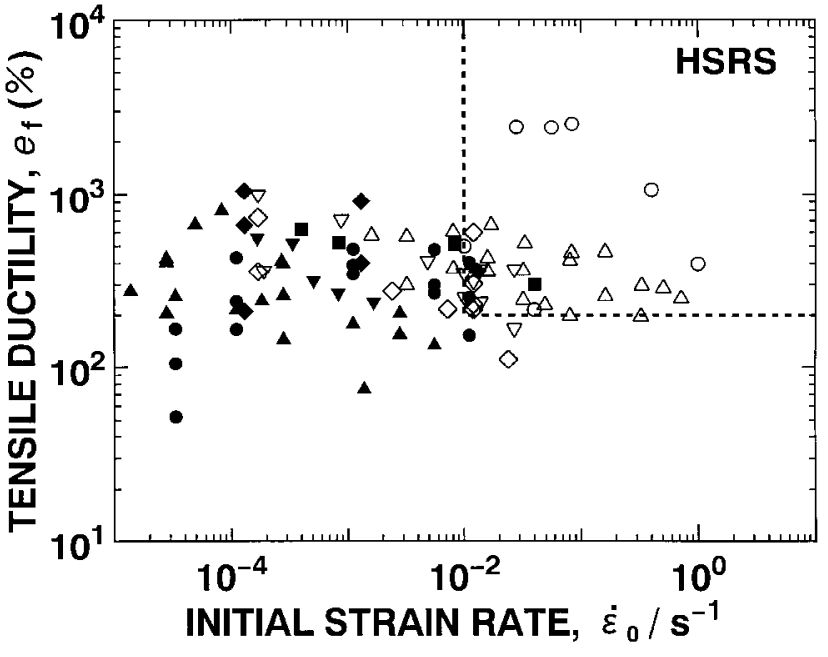

Fig. 4. Tensile ductility as a function of the initial strain rate in undoped 3Y-TZP $(\boldsymbol{\Delta}), \mathrm{ZrO}_{2}$-dispersed $\mathrm{Al}_{2} \mathrm{O}_{3}(\boldsymbol{\nabla}),{ }^{12)}$ and the materials listed in Table 2. The data for undoped 3Y-TZP were taken from sources listed in Ref. 53.

tem consisting of tetragonal $\mathrm{ZrO}_{2}, \alpha-\mathrm{Al}_{2} \mathrm{O}_{3}$ and $\mathrm{MgO} \cdot \mathrm{Al}_{2} \mathrm{O}_{3}$ spinel, where $\mathrm{MgO} \cdot \mathrm{Al}_{2} \mathrm{O}_{3}$-spinel is expected to supply $\mathrm{Al}^{3+}$ and $\mathrm{Mg}^{2+}$ to the $\mathrm{ZrO}_{2}$ phase and $\mathrm{Mg}^{2+}$ to the $\mathrm{Al}_{2} \mathrm{O}_{3}$ phase.

We prepared $30 \mathrm{vol} \% \mathrm{MgAl}_{2} \mathrm{O}_{4}-\mathrm{ZrO}_{2}(3 \mathrm{Y})^{47), 48}$ and 40 $\mathrm{vol} \% \mathrm{ZrO}_{2}(3 \mathrm{Y})-30 \mathrm{vol} \%\left(\mathrm{MgO} \cdot 1.1 \mathrm{Al}_{2} \mathrm{O}_{3}\right)-\mathrm{Al}_{2} \mathrm{O}_{3}{ }^{44)}$ from commercial powders. In the former, we applied colloidal processing to $\mathrm{MgAl}_{2} \mathrm{O}_{4}$ and $\mathrm{ZrO}_{2}(3 \mathrm{Y})$ powders. In the latter, we applied conventional processing to $\mathrm{ZrO}_{2}(3 \mathrm{Y}), \mathrm{MgO}$ and $\mathrm{Al}_{2} \mathrm{O}_{3}$ powders. Sintering at $1400^{\circ} \mathrm{C}$ for $1-2 \mathrm{~h}$ resulted in densified bodies with grain sizes of $0.29 \mu \mathrm{m}\left(\mathrm{ZrO}_{2}\right)$ and $0.42 \mu \mathrm{m}$ $\left(\mathrm{MgAl}_{2} \mathrm{O}_{4}\right)$ for the dual-phase composite and $0.28 \mu \mathrm{m}\left(\mathrm{ZrO}_{2}\right.$ and spinel $)$ and $0.45 \mu \mathrm{m}\left(\alpha-\mathrm{Al}_{2} \mathrm{O}_{3}\right)$ for the tri-phase composite. In the latter material the spinel phase was formed by chemical reaction between the $\mathrm{MgO}$ and $\mathrm{Al}_{2} \mathrm{O}_{3}$ powders. The grain size of each phase becomes smaller than that obtained by the sintering of each phase alone, particularly in the $\mathrm{Al}_{2} \mathrm{O}_{3}$ and spinel phases. Compared to the monolithic Y-TZP plotted in Fig. 4, although a higher temperature is necessary for sintering and deformation, the composites sustained noticeably higher strain rates and larger tensile elongation. As listed in Table 2, the available strain rate and tensile ductility reached $10^{-1}-10^{0} \mathrm{~s}^{-1}$ and $390-2500 \%$, respectively.

4.4 New aspects appearing in deformed microstructure In the composite materials described above, inspection of deformed microstructure has revealed some noticeable aspects in the $\mathrm{ZrO}_{2}(\text { Fig. 5 })^{44), 46)}$ and spinel ${ }^{48)}$ grains: dense intragranular dislocations and dislocation-relating substructures such as subboundaries. Elongation along the stress axis was also found in the spinel grains (Fig. 6). ${ }^{47), 48)}$ Such dislocation substructures and grain elongation were not found in undeformed materials. Thus, the observed aspects indicate that the grains of these phases are not perfectly rigid, that is, the grains is deformed by dislocation mechanisms to some extent during high-strain-rate loading.

Another notable feature appeared in cavitation

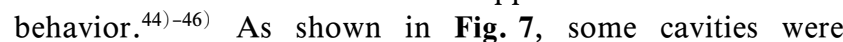
extremely elongated along the stress axis and micrometer sized cavities were rather sparse in the remaining matrix. Such a microstructure should appear when a small number of residual defects grew with plastic flow under strongly suppressed cavity nucleation. If cavity nucleation is active as observed in con- 


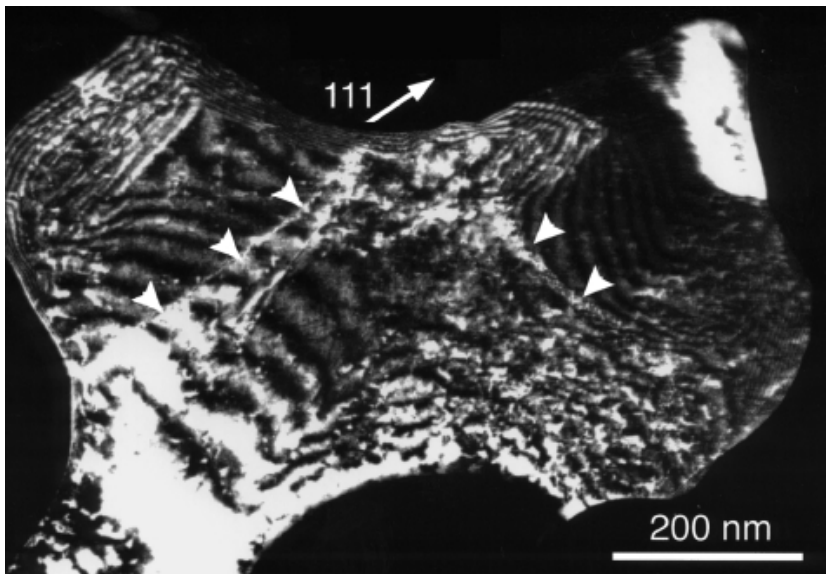

Fig. 5. A dark field transmission electron micrograph of a $\mathrm{ZrO}_{2}$ spinel- $\mathrm{Al}_{2} \mathrm{O}_{3}$ composite ${ }^{44)}$ deformed at $1650^{\circ} \mathrm{C}$ and at $1 \mathrm{~s}^{-1}$, showing the formation of dislocation substructures in a $\mathrm{ZrO}_{2}$ grain.

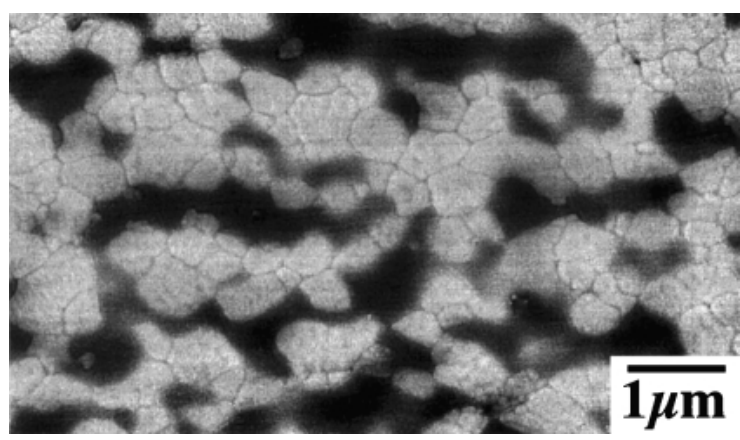

Fig. 6. Grain shapes after superplastic deformation in a $\mathrm{MgAl}_{2} \mathrm{O}_{4}$ dispersed $\mathrm{ZrO}_{2}{ }^{47)}$ While the white zirconia grains are euqiaxed after deformation, the dark spinel grains are noticeably elongated by deformation. Tensile axis is horizontal.

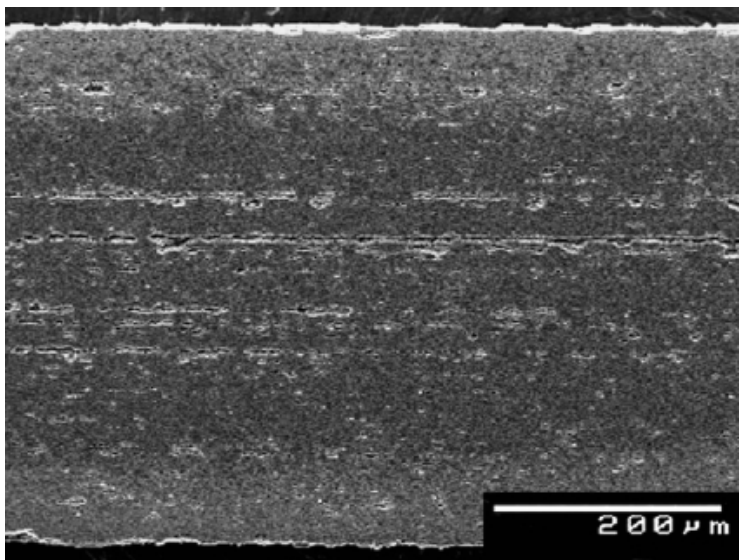

Fig. 7. Elongated cavities in a $\mathrm{ZrO}_{2}-\mathrm{MgO} \cdot \mathrm{Al}_{2} \mathrm{O}_{3}-\mathrm{Al}_{2} \mathrm{O}_{3}$ composite deformed to $2500 \%$ at $1650^{\circ} \mathrm{C}$ and at $0.1 \mathrm{~s}^{-1}$. ${ }^{45}$ ) Comparison with Fig. 2(b) shows suppressed cavitation and the absence of cracking perpendicular to the stress axis.

ventional materials (Fig. 2), a large number of micrometersized voids must grow from cavity nuclei during superplastic deformation. The void growth must be followed by coalesce and microcracking ${ }^{9), 10), 12), 18)}$ along the direction normal to the stress axis (Fig. 2(b)).

Thus, the dislocation substructures and the cavitation behavior indicate that the grains of $\mathrm{ZrO}^{2}$ and $\mathrm{MgAl}_{2} \mathrm{O}_{4}$ in the composites should contribute to the relaxation of stress concentrations around the multiple grain junctions and/or phase boundaries. Although further studies are desirable for this issue, the experimental results indicate that the dispersion of some secondary phases may provide a potential way for enhancing HSRS in oxide ceramics. This is an additional factor desirable for HSRS and noted as factor (h) in Table 1.

\section{Concluding remarks}

High-strain-rate superplasticity is now intentionally attainable in tetragonal zirconia and some composites synthesized from $\mathrm{ZrO}_{2}, \mathrm{Al}_{2} \mathrm{O}_{3}$ and $\mathrm{MgO}_{2}$. For this attainment, the knowledge about superplastic deformation, cavitation and dynamic grain growth emphasizes the importance of simultaneously controlling the following factors: the initial grain size, the number of residual defects, diffusivity, dynamic grain growth and the homogeneity of microstructure. Recent trials indicate that grains of $\mathrm{ZrO}_{2}$ and spinel phases dispersed in the composites may contribute to stress relaxation around multiple grain junctions and hence the suppression of cavity nucleation during high-strain-rate deformation. For industrial application, further studies are desirable on lowering the temperature available to high-strain-rate superplasticity in composite materials and on establishing a technology for high-strain-rate plastic forming of ceramics.

\section{References}

1) Wakai, F., Sakaguchi, S. and Matsuno, Y., Adv. Ceram. Mater., Vol. 1, pp. 259-263 (1986).

2) Barnes, A. J., Mater. Sci. Forum, Vols. 357-359, pp. 3-16 (2001).

3) Langdon, T. G., Mater. Sci. Forum, Vols. 304-306, pp. 13-20 (1999).

4) Higashi, K., Mater. Sci. Forum, Vols. 357-359, pp. 345-356 (2001).

5) Wakai, F., Shinoda, Y., Ishihara, S. and DominiguezRodriguez, A., Acta mater., Vol. 50, pp. 1177-1186 (2002).

6) Wakai, F., J. Ceram. Soc. Japan, Vol. 112, pp. 472-476 (2004).

7) Gifkins, R. C., J. Mater. Sci., Vol. 13, pp. 1926-1936 (1978).

8) Sato, E. and Kuribayashi, K., ISIS Int., Vol. 33, pp. 825-832 (1993).

9) Schissler, D. J., Chokshi, A. H., Nieh, T. G. and Wadsworth, J., Acta metal. mater., Vol. 39, pp. 3227-3236 (1991).

10) Chokshi, A. H., Nieh, T. G. and Wadsworth, J., J. Am. Ceram. Soc., Vol. 74, pp. 869-873 (1991).

11) Langdon, T. G. and Ma, Y., Acta metall. mater., Vol. 42, pp. 2753-2761 (1993).

12) Hiraga, K., Nakano, K., Suzuki, T. S. and Sakka, Y., J. Am. Ceram. Soc., Vol. 85, pp. 2763-2770 (2002).

13) Wakai, F. and Kato, H., Adv. Ceram. Mater., Vol. 3, pp. 71-75 (1988).

14) Riedel, H., "Fracture at High Temperatures," Springer-Verlag, Germany (1987) pp. 3-246.

15) Chan, K. S. and Page, R. A., J. Am. Ceram. Soc., Vol. 76, pp. 803-826 (1993).

16) Evans, A. G., Rice, J. R. and Hirth, J. P., J. Am. Ceram. Soc., Vol. 63, pp. 368-375 (1980).

17) Sakka, Y., Oishi, Y., Ando, K. and Morita, S., J. Am. Ceram. Soc., Vol. 74, pp. 2610-2614 (1991).

18) Hiraga, K. and Nakano. K., Z. Metallkude., Vol. 95, pp. 559-564 (2004).

19) Hiraga, K. and Nakano, K., Mater. Sci. Forum, Vols. 243-245, pp. 387-392 (1997).

20) Hiraga, K., Nakano, K., Suzuki, T. S. and Sakka, Y., Mater. 
Sci. Forum, Vols. 357-359, pp. 193-198 (2001).

21) Hancock, W., Metal Sci., Vol. 10, pp. 319-325 (1976).

22) Kim, B.-N., Hiraga, K., Sakka, Y. and Ahn, B.-W., Acta mater., Vol. 47, pp. 3433-3439 (1999).

23) Kim, B.-N., Hiraga, K., Morita, K. and Sakka, Y., Acta mater., Vol. 49, pp. 887-895 (2001).

24) Morita, K. and Hiraga, K., Acta mater., Vol. 50, pp. 1075-1085 (2002).

25) Chen, I.-W. and Xue, L.-A., J. Am. Ceram. Soc., Vol. 73, pp. 2585-2609 (1990).

26) Jimenz-Melendo, M., Dominguez-Rodriguez, A. and BravoLeon, A., J. Am. Ceram. Soc., Vol. 81, pp. 2761-2776 (1998).

27) Sakuma, T., Adv. Quantum Chem., Vol. 42, pp. 23-33 (2003).

28) Nakano, M., Mimurada, J., Sasaki, K., Ikuhara, Y. and Sakuma, T., Mater. Sci. Forum, Vols. 357-359, pp. 141-146 (2001).

29) Nakatani, K., Nagayama, H., Yoshida, H., Yamamoto, T. and Sakuma, T., Scripta. Mater., Vol. 49, pp. 791-795 (2003)

30) Kuwabara, A., Yokota, S., Ikuhara, Y. and Sakuma, T., Mater. Sci. Forum, Vols. 357-359, pp. 399-404 (2001).

31) Nakatani, K., Nagayama, H., Yoshida, H., Yamamoto, T. and Sakuma, T., Mater. Sci. Forum, Vols. 447-448, pp. 335-340 (2004).

32) Kuwabara, A., Yokota, S., Ikuhara, Y. and Sakuma, T., Mater. Trans., Vol. 43, pp. 2468-2472 (2004).

33) Kuwabara, A., Nakano, M., Yoshida, H., Ikuhara, Y. and Sakuma, T., Acta mater., Vol. 52, pp. 5563-5569 (2004).

34) Kuwabara, A., Yokota, S., Ikuhara, Y. and Sakuma, T. Mater. Trans., Vol. 45, pp. 2144-2149 (2004).

35) Kajihara, K., Yoshizawa, Y. and Sakuma, T., Acta metall. mater., Vol. 43, pp. 1235-1242 (1995).

36) Oka, K., Tabuchi, N. and Takashi, T., Mater. Sci. Forum, Vols. 304-306, pp. 451-458 (1999).

37) Suzuki, T. S., Sakka, Y., Morita, K. and Hiraga, K., Scripta.
Mater., Vol. 43, pp. 705-710 (2000).

38) Sato, E., Morioka, H., Kuribayashi, K. and Sundararaman, D., J. Mater. Sci., Vol. 34, pp. 4511-4518 (1999).

39) Chokshi, A. H., Yoshida, H., Ikuhara, Y. and Sakuma, T., Mater. Lett., Vol. 57, pp. 4196-4201 (2003).

40) Ikuhara, Y., Thavorniti, P. and Sakuma, T., Acta mater., Vol. 45, pp. 5275-5284 (1997).

41) Zhao, J., Ikuhara, Y. and Sakuma, T., J. Am. Ceram. Soc., Vol. 81, pp. 2087-2092 (1998).

42) Sakka, Y., Suzuki, T. S., Morita, K., Kim, B.-N., Hiraga, K. and Moriyoshi, Y., Adv. Eng. Mater., Vol. 5, pp. 130-133 (2003).

43) Sakka, Y., Ishii, T., Suzuki, T. S., Morita, K. and Hiraga, K., J. Eur. Ceram. Soc., Vol. 24, pp. 449-453 (2004).

44) Kim, B.-N., Hiraga, K., Morita, K. and Sakka, Y., Nature, Vol. 413, pp. 288-291 (2001).

45) Kim, B.-N., Hiraga, K., Morita, K., Sakka, Y. and Yamada, T., Scripta. Mater., Vol. 47, pp. 775-779 (2002).

46) Kim, B.-N., Hiraga, K. and Morita, K., Mater. Sci. Forum, Vols. 426-432, pp. 2729-2734 (2003).

47) Morita, K., Hiraga, K. and Sakka, Y., J. Am. Ceram. Soc., Vol. 85, pp. 1900-1902 (2002).

48) Morita, K., Hiraga, K., Kim, B.-N. and Sakka, Y., Mater. Trans., Vol. 45, pp. 2073-2077 (2004).

49) Lange, F. F., J. Am. Ceram. Soc., Vol. 72, pp. 3-15 (1989).

50) Cesarano, J., III, Aksay, I. A. and Bleier, A., J. Am. Ceram. Soc., Vol. 71, pp. 250-255 (1988).

51) Tsurui, K. and Sakuma, T., Scripta Mater., Vol. 34, pp. 443-447 (1996).

52) Harmer, M. P., Chan, H. M. and Miller, G. A., J. Am. Ceram. Soc., Vol. 75, pp. 1715-1728 (1992).

53) Kim, W.-J., Wolfenstine, J. and Sherby, O. D., Acta metall. mater., Vol. 39, pp. 199-208 (1991). 